Original article

https://www.journal-imab-bg.org

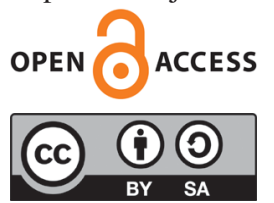

\title{
SURGICAL APPROACHES TO THE SHOULDER JOINT IN UNIPOLAR POST FRACTURE ENDOPROSTHESIS REPLACEMENT
}

\author{
Ivaylo Mitkovski \\ Orthopaedics and Traumatology Department, St. Anna General Active Treatment \\ Hospital, Orthopaedics and Traumatology Department, Medical University- \\ Varna, Bulgaria.
}

\begin{abstract}
This notification is intended to present our experience in applying various anatomic landmarks and approaches to the shoulder joint in unipolar post fracture endoprosthesis replacement.

MATERIALS AND METHODS: The period of monitoring includes the last 5 years. For this period, 35 shoulder joint aloplastics after a proximal shoulder fracture have been performed at the Orthopaedics and Traumatology Department at the Medical University - Varna, St. Anna General Active Treatment Hospital Base. The patients were in the group above 70 years of age; of them, 30 were women, and 5 were men. 32 hemiprostheses and 3 bipolar prostheses were implanted.

RESULTS: During the unipolar endoprosthesis replacement, we have used various approaches to the shoulder joint. To process the results of the arthroplastics performed after the proximal humerus fracture, the Constant Shoulder Score method was used with a Questionnaire Card. This Questionnaire Card investigates the patient's condition on the fourth week after the intervention. The level of pain, activity and motions in the shoulder are examined. Each one of the indexes gives the respective estimation, as a result of which the patient's status is summarized. This status varies from "bad" to "excellent". The other method used for a statistical result processing was VAS (Visual analogue scale of pain).

CONCLUSION: Using various approaches to shoulder joint in aloplastics depends on the reason which has led to this aloplastics, on the surgeon's experience and on knowing the anatomic details of the area affected.
\end{abstract}

Keywords: Humeral Fractures, Shoulder Replacement Arthroplasty, Joints, Dislocation Fracture, Shoulder Prosthesis, Surgical Approaches,

\section{INTRODUCTION}

The proximal humerus fractures represent $4-5 \%$ of all fractures. These fractures are the third most often location in elderly patients after the proximal femoral bone and the distal radial bone. Their incidence has increased significantly after the 70's of the 20th century, especially in women, according to a Finnish study [1]. Arguments conclude that if this trend keeps on growing and in the context of population ageing, the proximal shoulder bone fractures incidence shall be increased threefold until 2030 . In $80 \%$ of the cases [2], fractures in the proximal humerus end are slightly dislocated or not dislocated at all. Fragments remain on their places held by the rotator cuff, joint capsule and the periosteum [3]. Since these fragments remain stable, the fractures can successfully be treated conservatively. Unfortunately, such type of treatment is not applicable to $15 \%$ of the patients with unstable fractures, in which a high-energy trauma is responsible for the great dislocation. The trauma type and the dislocation degree are the two causes for often unsatisfactory results because of pains, limited motions and loss of strength. In order to restore the anatomy close to normal, blood reposition with internal fixation is a method of choice for unstable fractures. Surgical treatment, however, is difficult and problematic because of the difficult access to the fracture and the large fragmentation of pieces. A proximal shoulder bone fracture, which disturbs blood supply of the humeral head, may require placement of a prosthesis. In such cases, hemiarthroplastics is a logical approach.

\section{MATERIALS AND METHODS:}

During the endoprosthesis replacement in patients at the Orthopaedics and Traumatology Clinic, St. Anna General Active Treatment Hospital, we have used several different approaches to the shoulder joint.

ANTERIOR DELTOID-PECTORAL APPROACH

A skin cut is performed along the sulcus deltoidopectoralis [4] (Fig. 1). 
Fig. 1. Sulcus Deltoidopectoralis - Skin Cut

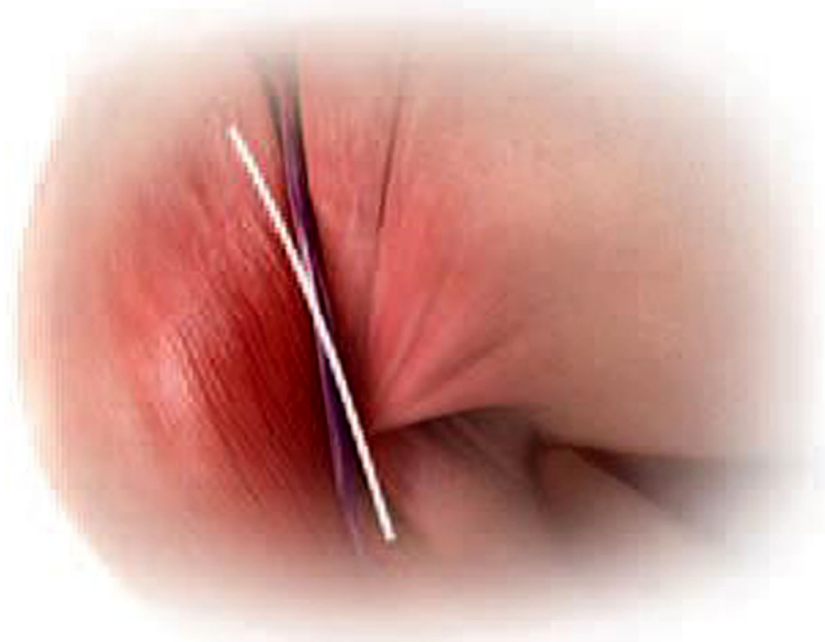

After cutting the skin and subcutaneous tissue, the sulcus between $\mathrm{m}$. deltoideus and $\mathrm{m}$. pectoralis major, filled with fatty tissue, can be seen. There lies v. cefalica, over the anterior edge of m. Deltoideus (Fig. 2).

Fig. 2. Vena Cefalica

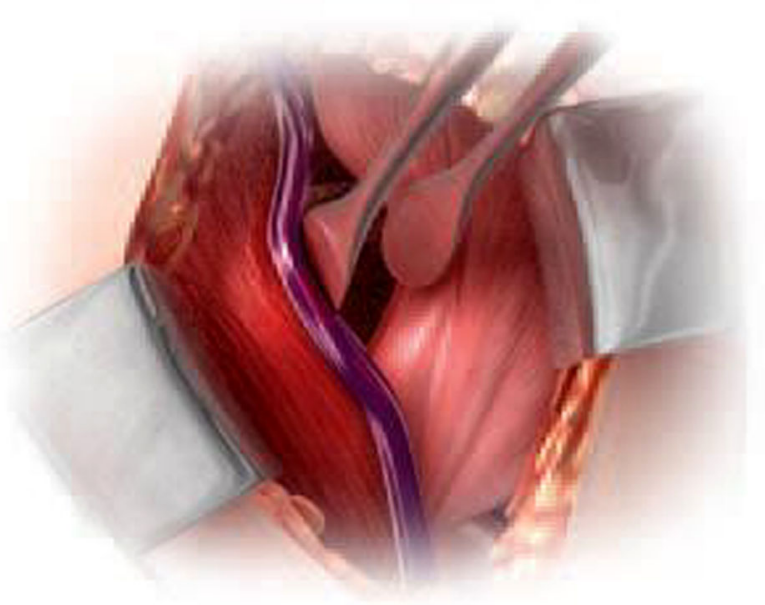

Another landmark for the border between both muscles is the different direction of their muscular fibres (Fig. 3 ). The m. deltoideus fibres are situated from the bottom upwards, whereas the m. pectoralis fibres are situated transversely.V.cefalica can be turned aside together with the deltoid muscle to the outside, or can be ligated. During the penetration in depth, the tendon of $\mathrm{m}$. biceps brahii short head is revealed. This tendon can be turned aside or cut and after that attached again.
Fig. 3. MusculusDeltoideus and Musculus Pectoralis Major

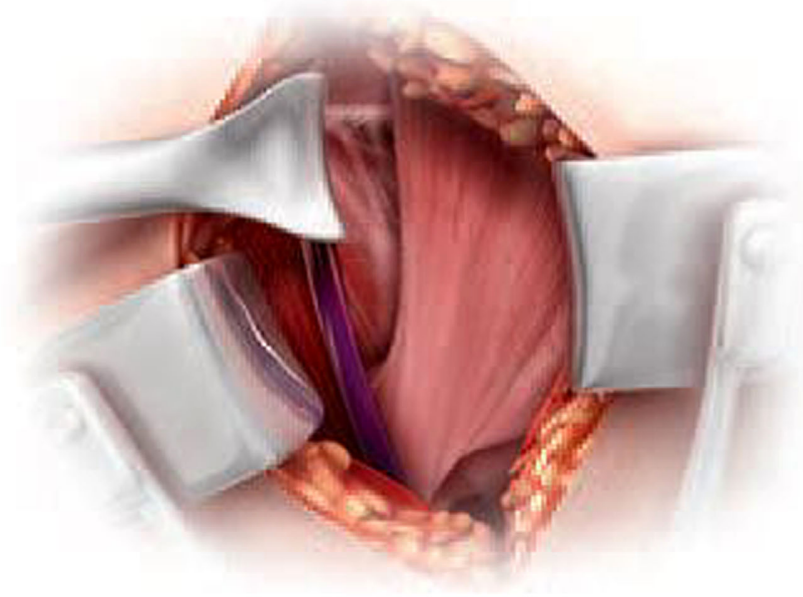

M. subscapularis is revealed, and if it is separated together with the small tubercle, it is turned aside medially, and if it is not, it is cut at $1.5 \mathrm{~cm}$ from its place of attachment (Fig. 4).

Fig. 4. Cutting of Musculus subscapularis

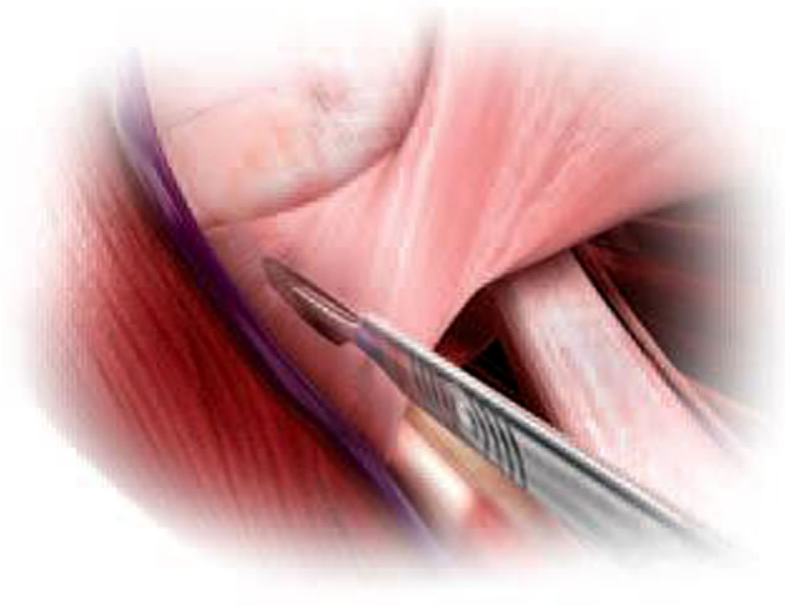

ANTERIOR LATERAL TRANS DELTOID APPROACH

A skin cut is performed laterally from the deltoidpectoral sulcus [5, 6] (Fig. 5, Fig. 6). 
Fig. 5. Deltoid-Pectoral Sulcus

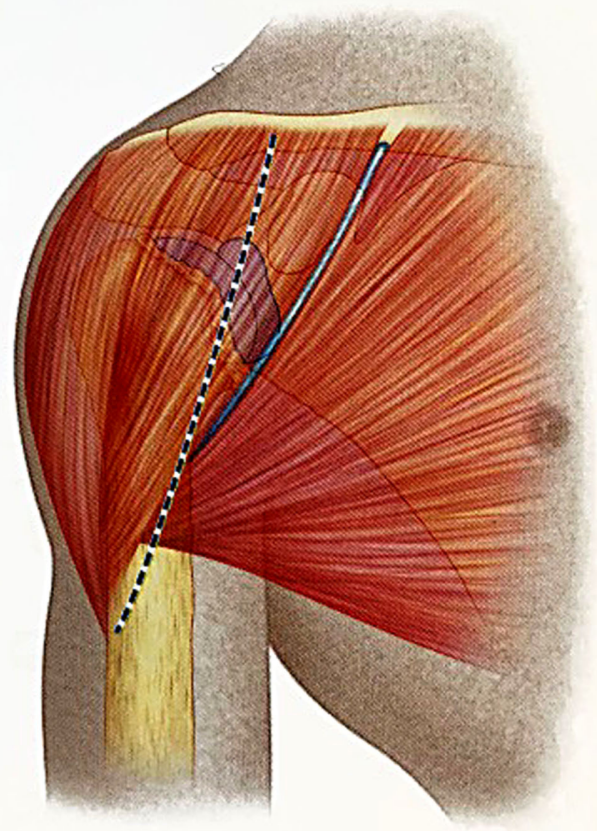

Fig. 6. Anterior Lateral Trans Deltoid Approach Skin Cut

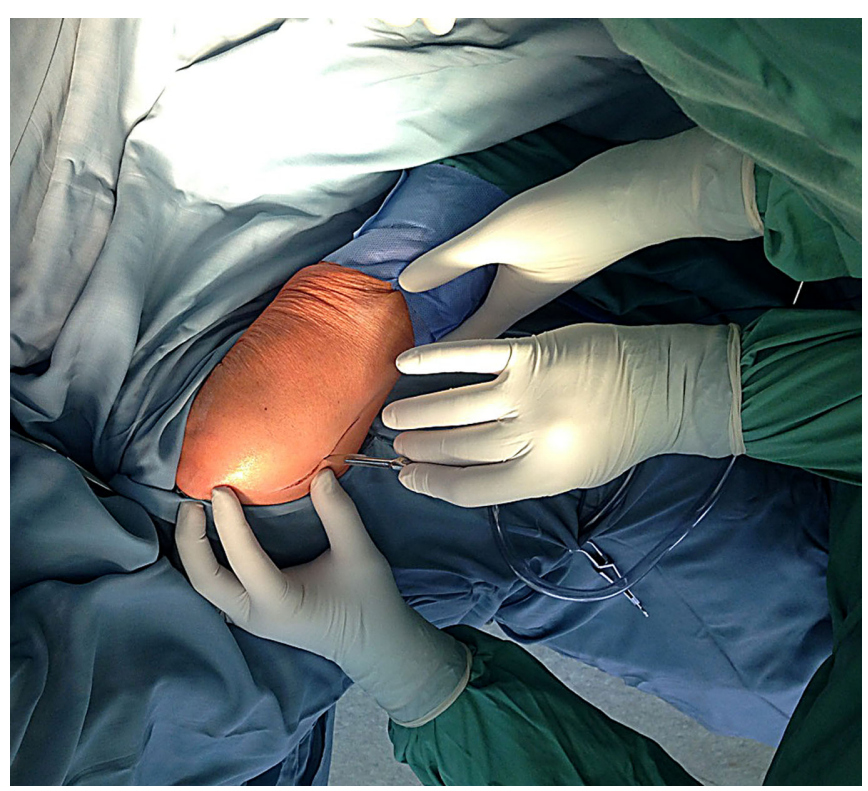

$\mathrm{N}$. musculocutaneous is revealed and is turned aside together with the coracobrachial muscle. The penetration between the $\mathrm{m}$. deltoideus is performed without cutting them in order to preserve their innervation and prevent any possibility of subsequent atrophy (Fig. 7). The next steps are identical with those at the anterior deltoid-pectoral approach.
Fig. 7. The Penetration Between the Musculus Deltoideus Without Cutting

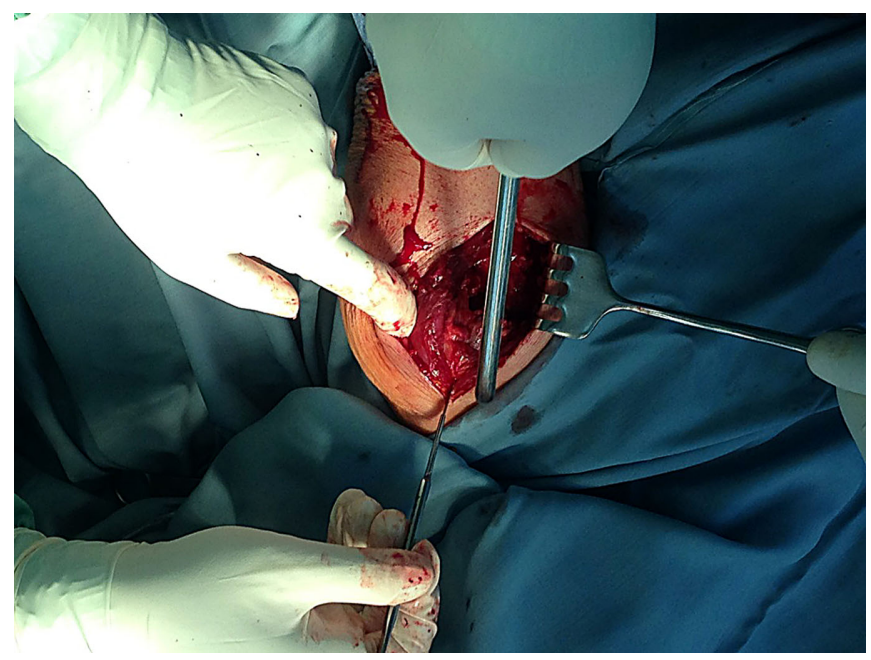

\section{UPPER LATERAL APPROACH}

The skin cut is $10-12 \mathrm{~cm}$, it could be performed close to the beginning or close to the end of the acromion lateral edge, or in the lateral direction [7] (Fig. 8). Following the subcutaneous dissection, anterior and middle deltoid muscular ligaments, located towards the acromion lateral end, are detached, using a rounded dissection [8].

Fig. 8. Upper Lateral Approach

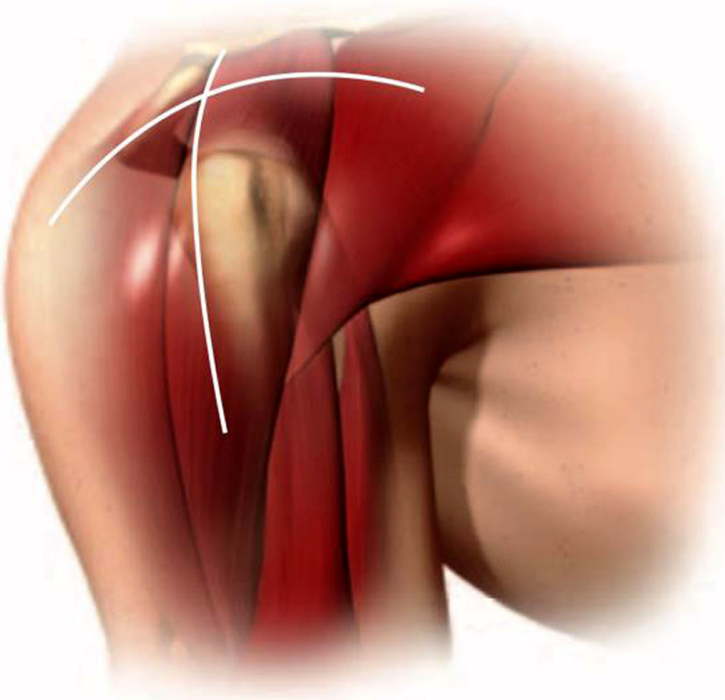

The dissection starts on the acromioclavicular joint level, on 5-7 $\mathrm{mm}$ after the acromion top, and continues straight laterally down along the deltoid muscle. It should not go on more than $4 \mathrm{~cm}$ from the deltoid muscle's external part, in order to protect $n$. axillary, which is located below the subacromial bursa fold. 
When the subacromial bursa is visible, a careful longitudinal pull away along the extremity length allows a retractor to be placed in the subacromial space (Fig. 9). Then the anterior deltoid part is released from the acromial insertion to the acromioclavicular joint. Detaching the deltoid from the acromion anterior part may include a small part of the bone, in order to facilitate restoration and to protect the deltoid muscle. After that, the extremity is rotated outwards, and the head is moved onwards and upward in order to perform a correct positioning. If the biceps is still visible, a tenotomy or a tenodesis has to be performed $[9,10,11]$. M. subscapularis, m. teres minor and $\mathrm{m}$. infraspinatus are held when visible. A partial detachment of $\mathrm{m}$. subscapularis could be performed, when it is hard to obtain a larger dislocation of the humerus.

Fig. 9. Subacromial Bursa

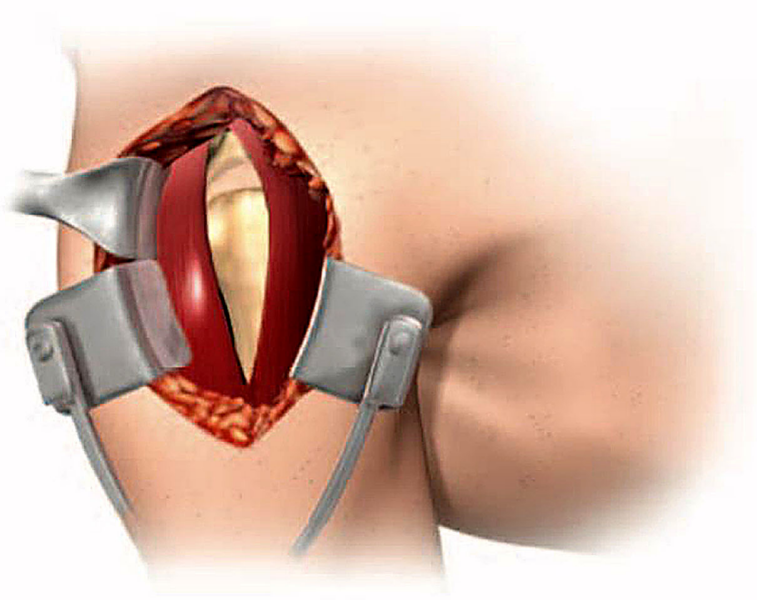

\section{LATERAL TRANS DELTOID APPROACH}

Basically, at this approach, the $\mathrm{n}$. axcilaris passage should be taken into consideration. The n.axcilaris goes from the back to the front transversely to the muscular fibres to about $5 \mathrm{~cm}$ from the acromioclavicular joint and the beginning of the deltoid muscle. Therefore, the longitudinal separation of muscular fibres should be no more than 3-4 cm from the muscle beginning (Fig. 10).

Fig. 10. Lateral Trans Deltoid Approach and NervusAxcilaris
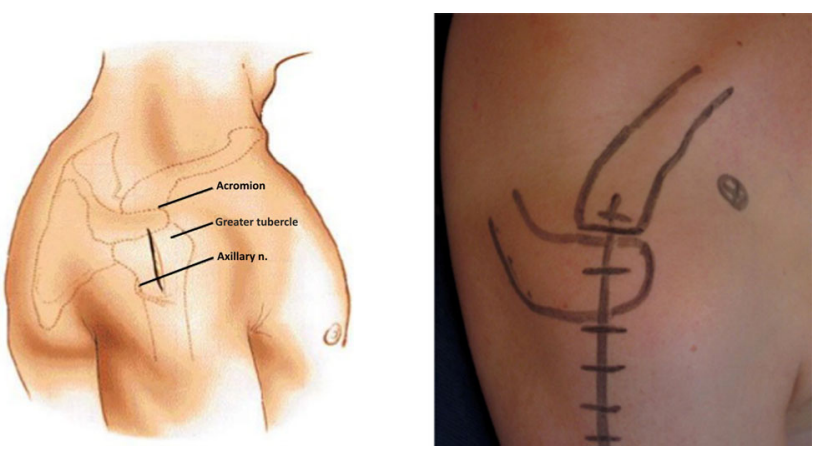

\section{CONCLUSION:}

Using a certain approach to the shoulder joint at unipolar post fracture endoprosthesis replacement depends on several factors. On the one hand, from the type of the endoprosthesis used - monoblock, bicomponent or reverse prosthesis. The surgeon's experience and preferences are essential. On the other hand, the available working base and surgical equipment are also substantial.

The main approaches to the shoulder joint, which we use most often in cases of unipolar post fracture endoprosthesis replacement, are the deltoid-pectoral approach and the anterior-lateral trans deltoid approach.
REFERENCES:

1. Palvanen M, Kannus P, Niemi S, Parkkari J. Update in the epidemiologyof proximal humeral fractures. Clin Orthop Relat Res. 2006 Jan;442:87-92. [PubMed] [Crossref]

2. Takov E, Tivchev P. [The Fracture diagnostics and treatment.] Venel (Bulgaria). 1996. [in Bulgarian]

3. Foster RJ, Dixon GL Jr, Bach AW, Appleyard RW, Green TM. Internal fixation of fractures and non-unions of the humeral shaft. Indications and results in a multi-center study. $J$ Bone Joint Surg Am. 1985 Jul;67(6):857-64. [PubMed]

4. Lädermann A, Lo EY, Schwitzguébel AJ, Yates E. Subscapularis and deltoid preserving anterior approach for reverse shoulder arthro- plasty. Orthop Traumatol Surg Res. 2016 Nov;102(7):905-908. [PubMed] [Crossref]

5. Marinello PG, Amini MH, Peers S, O’Donnell J, Iannotti JP. Reverse total shoulder arthroplasty with combined deltoid reconstruction in patients with anterior and/or middle deltoid tears. J Shoulder Elbow Surg. 2016 Jun;25(6):936-41. [PubMed] [Crossref]

6. Hoppenfeld S, de Boer P, Buckley R. Surgical Exposures in Orthopaedics: The Anatomic Approach. 5 th ed. Wolters Kluwer. October 14, 2016.

7. Boichev B. [Orthopaedics and Traumatology Surgery.] Sofia: Medicina i Fizkultura. 1983; 135-42. [in
Bulgarian]

8. Duranthon LD, Vandenbussche E, Goubier JN, Augereau B. [The superolateral approach for shoulder prosthesis]. [in French] Rev Chir Orthop Reparatrice Appar Mot. 2002 Jun;88(4):415-9. [PubMed]

9. Hassan S, Patel V. Biceps tenodesis versus biceps tenotomy for biceps tendinitis without rotator cuff tears. $J$ Clin Orthop Trauma. 2019 MarApr;10(2):248-256. [PubMed] [Crossref]

10. Dines DM, Tuckman D, Dines J. Hemiarthroplasty for complex fourpart fracture of the proximal humerus: technical considerations and surgical technique. Univ Pennsyl Orthop J. 2002; 15:29-36. 
11. Hempfing A, Leunig $M$, Ballmer FT, Hertel R. Surgical landmarks to determine humeral head retrotorsion for hemiarthroplasty in fractures. J Shoulder Elbow Surg. 2001 Sep-Oct;10(5):460-3. [PubMed] [Crossref]

Please cite this article as: Mitkovski I. Surgical Approaches to the Shoulder Joint in Unipolar Post Fracture Endoprosthesis Replacement. J of IMAB. 2020 Jan-Mar;26(1):2916-2920. DOI: https://doi.org/10.5272/jimab.2020261.2916

Received: 21/03/2019; Published online: 17/02/2020

Addresses for correspondence:

Dr. Ivaylo Mitkovski,

Medical University - Varna

55, Marin Drinov Str., 9002 Varna, Bulgaria,

E-mail: ivo_hm@abv.bg 